\title{
Tumours of the lymphoreticular system: nomenclature, histogenesis, and behaviour
}

\author{
N. F. C. GOWING \\ From the Royal Marsden Hospital, London
}

\section{Nomenclature and Classification}

Differentiation in neoplastic disease of the lymphoreticular system is inseparable from the problems of tumour nomenclature, and there can be few other aspects of oncology which have been so confused by 'a chaos of names' (Willis, 1967) and by such a multiplicity of suggested classifications. This is due in part to the fact that the lymphoreticular system is diffused widely through the body, and that many of its cells normally circulate in the peripheral blood and are involved in immune responses of various kinds including the synthesis of immunoglobulins. Thus, depending on which aspect of the neoplastic process is predominant, the disease may be named on the basis of the histological appearances of a tumour mass ('malignant lymphoma', 'lymphosarcoma' etc), according to cytological patterns in the peripheral blood and bone marrow ('leukaemia') or in accordance with changes in the plasma proteins (eg, 'macroglobulinaemia', 'heavy chain disease', 'alpha-chain disease'). In fact, in a given case, the histological findings, the blood picture, and the biochemical alterations are best regarded as different facets of a single underlying disease process. It is clear that close cooperation between histopathologists, haematologists, chemical pathologists, immunologists, and cytologists is vital in the proper assessment of an individual case, and in the establishment of a generally acceptable classification of lymphoreticular neoplasms. Furthermore, in any such (new) classification, consideration must be given to more recent advances in our knowledge of cell function and kinetics, such as the functional dichotomy of lymphocytes into thymic-dependent (T) and bursa-dependent (B) populations. RobbSmith (1938) formulated a detailed classification of the 'reticuloses' and 'reticulosarcomas' based on the differentiating cell type, and (in the case of the reticuloses) on which part of the lymph node was primarily involved in the cellular proliferation-the sinuses, the follicles, or the medulla. Unfortunately, the term 'reticulosis' has proved unsatisfactory, since it was used to cover benign reactive processes, conditions which are now considered to be neoplastic (such as follicular lymphoma) and lipid storage diseases. Gall and Mallory (1942) analysed 618 cases of malignant lymphoma and classified them according to cell type-stem cell, clasmatocytic, well differentiated lymphocytic and poorly differentiated lymphocytic. Follicular lymphoma and Hodgkin's disease comprised separate groups within the scheme. Following the suggestion of Rappaport, Winter, and Hicks (1956) that any cytological type of lymphoma could feature either a follicular (nodular) or a diffuse cellular arrangement, it was proposed that lymphomas with a follicular pattern should be fitted into the general classification of malignant lymphoma (Gall and Rappaport, 1958). Rappaport $(1964,1966)$ has extended the scope of this scheme to produce a comprehensive classification, including neoplastic proliferations of the myeloid, plasmacytic, and erythrocytic series.

In any classification, allowance must be made for the possible introduction of further types, or subtypes, as newly recognized clinicopathological entities become documented. For example, Burkitt's lymphoma is now regarded as a neoplasm distinct from other types of poorly differentiated lymphoblastic lymphoma (Burkitt and Wright, 1970) and differing in its cytology, morbid anatomy, clinical manifestations, and frequency of leukaemic transformation from the type of childhood lymphosarcoma more commonly seen in (for example) the United Kingdom (Wright, 1966; Wright, 1967). A further instance of a recently recognized subtype is the 'nodular sclerotic lymphosarcoma' described by Bennett and Millett (1969) and Millett, Bennett, Jelliffe, and Farrer-Brown (1969).

\section{RETICULUM CELL SARCOMA}

This term has been used loosely to designate any malignant lymphoid tumour featuring large cells which cannot be readily assigned to a particular differentiated series (lymphocytic, myelocytic, plasmacytic, etc). Indeed the nature and function of normal 'reticulum cells' have been long in doubt and there has been much confusion of terminology. 
Gall and Mallory (1942) pointed out that the type cell of 'reticulum cell sarcomas' has been interpreted variously as (1) an immature cell of the lymphocytic series, (2) a pluripotential cell, and (3) a relatively well differentiated cell of the monocytic or clasmatocytic series. Marshall (1956) believes that 'primitive reticular cells' can become 'activated' and are capable of differentiating into fibroblasts, lymphocytes, plasmacytes, all types of blood cells, and macrophages. However, in a discussion of reticulosarcomas, Marshall considers some of these tumours to consist of cells resembling the primitive reticular cells, and others to be anaplastic growths of indeterminate cell type. Rappaport (1966) follows Gall and Mallory (1942) in subdividing 'reticulum cell sarcomas' into undiffereritiated and histiocytic forms. Peckham and Cooper (1969) consider 'reticulum cell' to be synonymous with 'histiocyte'. Hartsock (1968) in a discussion of post-vaccinal lymphadenitis, uses the term 'reticular lymphoblast' for large cells with pyroninophilic cytoplasm and prominent nucleoli and which are probably transformed lymphocytes either of the B or T type. Okano, Azar, and Osserman (1966) speak of a 'plasmacytic reticulum cell sarcoma' in their report of a tumour, judged to be a reticulum cell sarcoma on the basis of its cytomorphology (in haematoxylin and eosin preparations) and reticulin formation, but featuring cytoplasmic pyroninophilia, abundant rough-surfaced endocytoplasmic reticulum, and the production of a myeloma-type protein demonstrated by electrophoretic analysis of the patient's serum.

Several workers now use the term 'reticulum cell sarcoma' as synonymous with malignant lymphoma of histiocytic type (Mathé, Gerard-Marchant, Texier, Schlumberger, Berumen, and Paintrand, 1970; Rosas-Uribe and Rappaport, 1972). Some of the histiocytic neoplasms feature abundant reticulin and collagen formation; such tumours have been called 'sclerosing reticulum cell sarcomas', and the production of collagen is in accord with the demonstration by Ozzello, Stout, and Murray (1963) that histiocytes may act as facultative fibroblasts (RosasUribe and Rappaport, 1972). On the other hand, Stein, Lennert, and Parwaresch (1972) analysed tissue homogenates of $\mathbf{2 8}$ malignant lymphomas and three myelomas for their content of immunoglobulins. Sixteen of the tumours showed a significantly increased immunoglobulin content compared with that of normal lymph node homogenates. They considered these 16 cases to be lymphomas of $B$ lymphocytes, although four had been classified as reticulum cell sarcomas histologically, and they concluded that 'the light-microscopical classification of reticulum cell sarcomas should be revised'.

It may be concluded that the term reticulum cell sarcoma embraces at least three tumour subtypes: (1) malignant lymphoma, histiocytic; (2) some malignant lymphomas of B lymphocytes; and (3) malignant lymphoma, undifferentiated. It would probably be wise to abandon the term if possible. The present meaningless status of the names 'reticulum cell sarcoma' and 'lymphosarcoma' has been stressed by Lukes (1968).

FOLLICULAR LYMPHOMA

The nature of this tumour and its status within the schemata of the malignant lymphomas have been subject to considerable controversy. Called 'follicular lymphoblastoma' by Baehr and Rosenthal (1927) and 'lymphoid follicular reticulosis' by Robb-Smith (1938), it was considered to be a distinct tumour type, although variation in the cellular composition of the neoplastic follicles was recognized (Gall, Morrison, and Scott, 1941) and transitions to other types of lymphoma, including Hodgkin's disease, were regarded as frequent (Custer and Bernard, 1948; Wetherley-Mein, Smith, Geake, and Anderson, 1952; Hurst and Meyer, 1961). Rappaport et al (1956) reviewed 253 cases of follicular lymphoma and concluded that any cytological type of malignant lymphoma could have either a nodular (follicular) or diffuse pattern; they suggested that follicular lymphomas could be integrated into the general classification of malignant lymphomas by using any one of the accepted cytological classifications for all lymphomas and adding the term 'follicular' or 'nodular' whenever this was indicated by the prevailing architectural pattern. Dorfman (1961) supported this proposed classification on the basis of enzyme histochemical findings in five cases of follicular lymphoma. Rappaport et al (1956) also observed a consistency in the cytological picture when the follicular lymphomas progressed into the diffuse forms. Furthermore, they found that when Hodgkin's disease became apparent in a patient on whom a diagnosis of follicular lymphoma had been made previously, re-examination of the original lymph node sections indicated that Hodgkin's disease (in a nodular form) had been present initially; they considered that transition to Hodgkin's disease from nodular lymphoma of another cellular type rarely, if ever, occurred.

However, the proposed classification of Rappaport et al (1956) has been challenged by Mori and Lennert (1969) who regard follicular lymphoma as a distinct tumour type, arising from germinal centre cells and for which they propose the term 'germinoblastoma'. This concept was supported by their electron microscopic studies. The cells comprising the nodules had large irregular nuclei, exhibiting deep indentations; long-branching, desmosome-connected reticulum 
cells were also present. The cells with deeply indented nuclei probably correspond to the 'notched nucleus cells' or 'haematogones' which may be found in the peripheral blood and bone marrow in cases of follicular lymphoma (Anday and Schmitz, 1952; Rosenthal, Dreskin, Vural, and Zak, 1952). Rappaport et al (1956) found these abnormal lymphocytes in 23 of 35 patients from whom blood smears were available; the total white cell counts in these patients ranged from 3400 to 33000 .

\section{Progressive Spread and Systematization of Malignant Lymphomas}

Progressive dissemination of a lymphoma, with the formation of multiple tumour masses, or diffuse systematization with involvement of the spleen, liver, and bone marrow, and the appearance of lymphoma cells in the peripheral blood, may occur without any decrease in cytological differentiation. Thus, two sequential lymph node biopsies from the same patient may show identical histological appearances, while the clinical, haematological, and immunological findings have changed dramatically. For this reason Lukes (1968) has stressed the importance of establishing a 'prognostic profile' in each case, taking into account facets other than histology alone. These other facets should include the clinical distribution of the lymphoma, the presence or absence of peripheral blood and bone marrow involvement, and the immunological status of the patient.

\section{Dedifferentiation and Increased Tumour Aggressiveness}

Increased clinical aggressiveness, associated with tumour dedifferentiation, is a well recognized phenomenon, as in the 'blast cell crisis' of a chronic myeloid leukaemia. Hodgkin's disease may progress into a more malignant form by depletion of the lymphocytic component and a steadily increasing dominance of mononucleated Hodgkin cells and Sternberg-Reed cells (Lukes, Butler, and Hicks, 1966). Follicular lymphoma may progress into a diffuse form of corresponding cellular composition, and a lymphoma of mixed cell type (lymphocytic/ histiocytic) may progress to 'reticulum cell sarcoma' by overgrowth of the malignant histiocytes (Rappaport, 1964).

Of considerable interest is the development of an apparently new and different type of lymphoreticular neoplasm during the course of a malignant lymphoma or leukaemia. Reported associations include Hodgkin's disease and acute myelocytic leukaemia (Osta, Wells, Viamonte, and Harkness, 1970), 5
Hodgkin's disease and acute lymphoblastic leukaemia (Lacher and Sussman, 1963), Hodgkin's disease and acute lymphosarcoma cell leukaemia (Burns, Stjernholm, and Kellermeyer, 1971), Hodgkin's disease and DiGuglielmo's leukaemia (Durant and Tassoni, 1967), Hodgkin's disease and chronic lymphocytic leukaemia (Oberfield, 1966; Tornyos, Macossay, and Gyorkey, 1967), plasma cell myeloma and acute monocytic leukaemia (Osserman and Lawler, 1966), and well differentiated lymphocytic lymphoma and acute myeloid leukaemia (Weiss, Brunning, and Kennedy, 1972).

The appearance of highly aggressive lymphoreticular tumours in patients with chronic lymphocytic leukaemia is an uncommon but well documented phenomenon, first described by Richter (1928). Lortholary, Boiron, Ripault, Levy, Manus, and Bernard (1964) presented four cases, reviewed the previous reports, and suggested the term 'Richter's syndrome' for this association. Three further cases were reported by Givler (1968). Some of the supervening tumours have been called 'reticulum cell sarcomas', while others have been diagnosed as Hodgkin's disease. The salient features of five cases of Richter's syndrome, seen at the Royal Marsden Hospital, are shown in the table. Two of

\begin{tabular}{|c|c|c|c|c|c|}
\hline Case & $\begin{array}{l}\text { Age } \\
\text { (yr) }\end{array}$ & Sex & $\begin{array}{l}\text { Known } \\
\text { Duration of } \\
\text { CLL before } \\
\text { Appearance } \\
\text { of Tumour } \\
(y r)\end{array}$ & $\begin{array}{l}\text { Predominant } \\
\text { Sites of } \\
\text { Involvement } \\
\text { by Sarcoma }\end{array}$ & $\begin{array}{l}\text { Survival } \\
\text { Time after } \\
\text { Diagnosis of } \\
\text { Sarcoma } \\
(m t h)\end{array}$ \\
\hline 1 & 55 & $\mathbf{M}$ & 3 & $\begin{array}{l}\text { Lymph } \\
\text { nodes, liver }\end{array}$ & $<6$ \\
\hline 2 & 48 & $\mathbf{M}$ & 7 & $\begin{array}{l}\text { Lymph } \\
\text { nodes, liver, } \\
\text { kidneys }\end{array}$ & $<6$ \\
\hline 3 & 59 & $\mathbf{F}$ & 7 & $\begin{array}{l}\text { Lymph } \\
\text { nodes, liver, } \\
\text { skin }\end{array}$ & $<6$ \\
\hline 4 & 66 & $\mathbf{M}$ & 6 & $\begin{array}{l}\text { Lymph } \\
\text { nodes }\end{array}$ & $<6$ \\
\hline 5 & 53 & $\mathbf{M}$ & 4 & $\begin{array}{l}\text { Lymph } \\
\text { nodes, liver }\end{array}$ & $<6$ \\
\hline
\end{tabular}

Table Richter's syndrome in chronic lymphocytic leukaemia

the tumours were considered to be undifferentiated malignant lymphomas, and the other three were judged to be malignant lymphomas of histiocytic type. In all five cases, death occurred within a few months of the second tumour becoming clinically manifest. The pathogenesis of the second neoplasm is a matter for speculation. A possible factor is immunological failure occasioned by the initial lymphoma or leukaemia. Various types of malignant tumour (including 'reticulum cell sarcoma') are 
known to occur in immunosuppressed organ transplant recipients, the incidence of the neoplasms being approximately 80 times greater than in the average population in a comparable age range (Penn and Starzl, 1972). Similarly, Fialkow, Klein, Gartler, and Clifford (1970) and Fialkow, Klein, and Clifford (1972) using an enzyme (glucose-6phosphate dehydrogenase) typing technique, demonstrated a clonal origin, for individual Burkitt tumours, and showed that a 'recurrent' Burkitt lymphoma probably represented a new tumour derived from a second malignant clone. The emergence of the second malignancy may have been conditioned by immunosuppression induced by the chemotherapy which had produced an apparently complete remission of the original lymphoma.

\section{T and B Lymphocytes and Lymphomas}

Following the demonstration of the two pathways of normal lymphoid differentiation, the thymic-( $T$ cell) and bursal-(B cell) dependent systems, it has been suggested that lymphoid malignancies may be classified (or subclassified) according to which system has given rise to the neoplastic cells (Cooper, Peterson, Gabriesen, and Good, 1966; Miller, 1967). The immunological abnormalities found in patients with Hodgkin's disease (Aisenberg, 1964; Aisenberg, 1966; Chase, 1966) point to a defect in the thymus system, and Hodgkin's disease may be a tumour of thymic-dependent cells (Cooper et al, 1966). However, the origin of Sternberg-Reed cells remains unsettled. Rappaport $(1964,1966)$ considers them to be altered (neoplastic) histiocytes. Braunstein, Frieman, and Gall (1958) and Braunstein, Frieman, Thomas, and Gall (1962a and b) supported this concept on the basis of enzyme histochemical studies, but others have found Sternberg-Reed cells to give much less intense staining results for nonspecific esterase and acid phosphatase when compared with normal, activated, or neoplastic histiocytes (Wright, 1964; Dorfman, 1961, 1964, 1972).

Tumours arising from the B cell system may feature increased immunoglobulin production with a raised level of plasma globulin, or the neoplastic cells may display functional dedifferentiation and hypoglobulinaemia may develop as systematization occurs and tumour cells progressively replace the normal. This sequence is common in patients with chronic lymphocytic leukaemia (Fairley and Scott, 1961). In plasmacytomas, biochemical dedifferentiation often parallels the degree of malignancy (Hobbs, 1971). Aisenberg and Bloch (1972) demonstrated cell surface IgM on leukaemic lymphocytes from 25 patients with chronic lymphocytic leukaemia and three with chronic lymphosarcoma cell leukae- mia, and on lymph node cells from three of four cases with lymphocytic lymphoma. They considered the findings to indicate a B cell origin of the leukaemia and lymphoma cells. Evidence in favour of a B cell origin for chronic lymphocytic leukaemic cells also comes from the work of Wilson and Nossal (1971) and Wybran, Chantler, and Fudenberg (1973).

Smith, Barker, Clein, and Collins (1973) have produced evidence suggesting that certain mediastinal lymphomas usually associated with leukaemic manifestations ('Sternberg sarcoma') are of thymic origin. Such cases may constitute a group of $\mathbf{T}$ cell leukaemias.

\section{Conclusion}

The problem of formulating a generally acceptable classification of lymphoreticular neoplasms based on cell differentiation remains unresolved. Histopathology alone is not adequate for such a classification. A nomenclature which will act as a meaningful channel of communication between pathologist and clinician can be achieved only through the close collaboration of histologists, haematologists, clinical pathologists, immunologists, and cytologists.

\section{References}

Aisenberg, A. C. (1964). Immunologic aspects of Hodgkin's disease. Medicine (Baltimore), 43, 189-193.

Aisenberg, A. C. (1966). Manifestations of immunologic unresponsiveness in Hodgkin's disease. Cancer Res., 26, 1152-1160.

Aisenberg, A. C., and Bloch, K. J. (1972). Immunoglobulins on the surface of neoplastic lymphocytes. New Engl. J. Med., 287, 272-276.

Anday, G. J., and Schmitz, H. L. (1952). Follicular lymphoma with transient leukemic phase. Arch. intern. Med., 89, 621-634.

Baehr, G., and Rosenthal, N. (1927). Malignant lymph follicle of hyperplasia of spleen and lymph nodes. (Abstr.). Amer. J. Path., 3, 550.

Bennett, M. H., and Millett, Y. L. (1969). Nodular sclerotic lymphosarcoma: a possible new clinico-pathological entity. Clin. Radiol., 20, 339-343.

Braunstein, H., Freiman, D. G., and Gall, E. A. (1958). A histochemical study of the enzymatic activity of lymph nodes. I. The normal and hyperplastic lymph node. Cancer (Philad.), 11, 829-837.

Braunstein, H., Freiman, D. G., Thomas, W., Jr., and Gall, E. A. (1962a). A histochemical study of the enzymatic activity of lymph nodes. II. Further investigation of normal and hyperplastic lymph nodes. Cancer (Philad.), 15, 130-138.

Braunstein, H., Freiman, D. G., Thomas, W., and Gall, E. A. (1962b). A histochemical study of the enzymatic activity of lymph nodes. III. Granulomatous and primary neoplastic conditions of lymphoid tissue. Cancer (Philad.), 15, 139-152.

Burkitt, D. P., and Wright, D. H. (1970). Burkitt's Lymphoma, p. 82, Livingstone, Edinburgh and London.

Burns, C. P., Stjernholm, R. L., and Kellermeyer, R. W. (1971). Hodgkin's disease terminating in acute lymphosarcoma cell leukemia. Cancer, 27, 806-811.

Chase, M. W. (1966). Delayed-type hypersensitivity and the immunology of Hodgkin's disease, with a parallel examination of sarcoidosis. Cancer Res., 26, 1097-1120.

Cooper, M. D., Peterson, R. D. A.,Gabrielsen, A. E., and Good, R. A. (1966). Lymphoid malignancy and development, differentiation, and function of the lymphoreticular system. Cancer Res., 26, vol. 2, 1165-1169. 
Custer, R. P., and Bernhard, W. G. (1948). The interrelationship of Hodgkin's disease and other lymphatic tumors. Amer. J. med. Sci., 216, 625-642.

Dorfman, R. F. (1961). Enzyme histochemistry of the cells in Hodgkin's disease and allied disorders. Nature (Lond.), 190, 925-926.

Dorfman, R. F. (1964). Enzyme histochemistry of normal, hyperplastic and neoplastic lymphoreticular tissues. In The Lymphoreticular Tumours; A symposium in Africa, Paris, 1963, edited by F. C. Roulet, p. 304-321. Karger, Basle and New York.

Dorfman, R. F. (1972). Biology of malignant neoplasia of the lymphoreticular tissues. J. reticuloendothelial Soc., 12, 239-256.

Durant, J. R., and Tassoni, E. M. (1967). Coexistent DiGuglielmo's leukemia and Hodgkin's disease. Amer. J. med., Sci., 254, 824-830.

Fairley, G. H., and Scott, R. B. '1961). Hypogammaglobulinaemia in chronic lymphatic leukaemia. Brit. med. J., 2, 920-924.

Fialkow, P. J., Klein, G., and Clifford, P. (1972). Second malignant clone underlying a Burkitt-tumour exacerbation. Lancet, 2 , 629-631.

Fialkow, P. J., Klein, G., Gartler, S. M., and Clifford, P. (1970). Clonal origin for individual Burkitt tumours. Lancet, 1 , 384-386.

Gall, E. A., and Mallory, T. B. (1942). Malignant lymphoma: a clinico-pathologic survey of 618 cases. Amer. J. Path., 18, 381-429.

Gall, E. A., Morrison, H. R., and Scott, A. T., (1941). The follicular type of malignant lymphoma: a survey of 63 cases. Ann. Intern. Med., 14, 2073-2090.

Gall, E. A., and Rappaport, H. (1958). In Proceedings of Seminar on Diseases of Lymph Nodes and Spleen, American Society of Clinical Pathologists, Chicago, p. 32.

Givler, R. L. (1968). Lymphocytic leukemia with coexistent localised reticulum cell sarcoma. Cancer (Philad.), 21, 1184-1192.

Hartsock, R. J. (1968). Postvaccinial lymphadenitis. Hyperplasia of lymphoid tissue that simulates malignant lymphomas. Cancer, 21, 632-649.

Hobbs, J. R. (1971). Immunocytoma o' mice an' men. Brit. Med. J., 2, 67-72.

Hurst, D. W., and Meyer, O. O. (1961). Giant follicular lymphoblastoma. Cancer, 14, 753-778.

Lacher, M. J., and Sussman, L. N. (1963). Leukemia and Hodgkin's disease. Ann. Int. Med., 59, 369-378.

Lortholary, P., Bioron, M., Ripault, P., Levy, J. P., Manus, A., and Bernard, J. (1964). Leucémie l ymphoïde chronique secondairement associée à une réticulopathie maligne, syndrome de richter. Nouv. Rev. franc. Hémat., 4, 621-644.

Lukes, R. J. (1968). The pathologic picture of the malignant lymphomas. In Proceedings of the International Conference on Leukemia-lymphoma, edited by C. J. D. Zarafonetis, pp. 333356. Lea and Febiger, Philadelphia.

Lukes, R. J., Butler, J. J., and Hicks, E. B. (1966). Natural history of Hodgkin's disease as related to its pathologic picture. Cancer (Philad.), 19, 317-344.

Marshall, A. H. E. (1956). An outline of the cytology and pathology of the reticular tissue. Oliver and Boyd, Edinburgh and London.

Mathé, G., Gerard-Marchant, R., Texier, J. L., Schlumberger, J. R., Berumen, L., and Paintrand, M. (1970). The two varieties of lymphoid tissue 'reticulosarcomas', histiocytic and histioblastic types. Brit. J. Cancer, 24, 687-695.

Miller, D. G. (1967). Immunological deficiency and malignant lymphoma. Cancer, 20, 579-588.

Millett, Y. L., Bennett, M. H., Jelliffe, A. M., and Farrer-Brown, G. (1969). Nodular sclerotic lymphosarcoma. A further review. Brit. J. Cancer, 23, 683-692.

Mori, Y., and Lennert, K. (1969). Electron Microscopic Atlas of Lymph Node Cytology and Pathology. Springer-Verlag, Berlin, Heidelberg and New York.

Oberfield, R. A. (1966). Coexistence of chronic lymphocytic leukemia and Hodgkin's disease. J. Amer. Med. Ass., 195, 865-867.

Okano, H., Azar, H. A., and Osserman, E. F. (1966). Plasmacytic reticulum cell sarcoma. Amer. J. Clin. Path., 46, 546-555.

Osserman, E. F., and Lawlor, D. P. (1966). Serum and urinary lysozyme (muramidase) in monocytic and monomyelocytic leukemia. J. Exp. Med., 124, 921-952.

Osta, S., Wells, M., Viamonte, M., and Harkness, D. (1970). Hodgkin's disease terminating in acute leukemia. Cancer (Philad.), 26, 795-799.

Ozzello, L., Stout, A. P., and Murray, M. R. (1963). Cultural characteristics of malignant histiocytomas and fibrous xanthomas. Cancer (Philad.), 16, 331-344.

Peckham, M. J., and Cooper, E. H. (1969). Proliferation characteristics of the various classes of cells in Hodgkin's disease. Cancer, 24, 135-146.

Penn, I., and Starzl, T. E. (1972). Malignant tumors arising de novo in immunosuppressed organ transplant recipients. Transplantation, 14, 407-417.

Rappaport, H. (1964). Classification of neoplastic diseases of the reticular system. In The Lymphoreticular Tumours in Africa; $A$ Symposium. Paris, 1963, edited by F. C. Roulet, pp. 394-409. Karger, Basle and New York.

Rappaport, H. (1966). Tumors of the hematopoietic system. Atlas of Tumor Pathology, Sect. 3, Fasc. 8). Armael Forces Institute of Pathology, Washington, D.C.

Rappaport, H., Winter, W. J., and Hicks, E. B. (1956). Follicular lymphoma. Cancer (Philad.), 9, 792-821.

Richter, M. N. (1928). Generalized reticular cell sarcoma of lymph nodes associated with lymphatic leukemia. Amer J. Path., 4, 285-292.

Robb-Smith, A. H. T. (1938). Reticulosis and reticulosarcoma: a histological classification. J. Path. Bact., 47, 457-480.

Rosas-Uribe, A., and Rappaport, H. (1972). Malignant lymphoma, histiocytic type with sclerosis (sclerosing reticulum cell sarcoma). Cancer (Philad.), 29, 946-953.

Rosenthal, N., Dreskin, O. H., Vural, I. L., and Zak, F. G. (1952). The significance of haematogones in blood, bone marrow and. lymph node aspiration in giant follicular lymphoblastomas Acta haemat. (Basel), 8, 368-377.

Smith, J. L., Barker, C. R., Clein, G. P., and Collins, R. D. (1973). Characterisation of malignant mediastinal lymphoid neoplasm (Sternberg sarcoma) as thymic in origin. Lancet, 1, 74-77.

Stein, H., Lennert, K., and Parwaresch, M. R. (1972). Malignant lymphomes of B-cell type. Lancet, $2,855-857$.

Tornyos, K., Macossay, C. R., and Gyorkey, F. (1967). Chronic lymphocytic leukemia and Hodgkin's disease in the same patient. Cancer (Philad.), 20, 552-557.

Weiss, R. B., Brunning, R. D., and Kennedy, B. J. (1972). Lymphosarcoma terminating in acute myelogenous leukemia. Cancer (Philad.), 30, 1275-1278.

Wetherley-Mein, G., Smith, P., Geake, M. R., and Anderson, H. J. (1952). Follicular lymphoma. Quart. J. Med., 21, 327-351.

Willis, R. A. (1967). Pathology of Tumours. 4th ed., p. 772. Butterworth, London.

Wilson, J. D., and Nossal, G. J. V. (1971). Identification of human $T$ and $B$ lymphocytes in normal peripheral blood and in chronic lymphocytic leukaemia. Lancet, 2, 788-791.

Wright, D. H. (1964). Cytology and histochemistry of the malignant lymphomas seen in Uganda. In The Lymphoreticular Tumours in Africa; A Symposium. Paris, 1963, edited by F. C. Roulet, pp. 291-303. Karger, Basle and New York.

Wright, D. H. (1966). Burkitt's tumour in England: a comparison with childhood lymphosarcoma. Int. J. Cancer, 1, 503-514.

Wright, D. H. (1967). Burkitt's tumor and childhood lymphosarcoma. Clin. Pediat., 6, 116-123.

Wybran, J., Chantler, S., and Fudenberg, H. H. (1973). Isolation of normal $T$ cells in chronic lymphatic leukaemia. Lancet, 1 , 126-129. 